\title{
Risk Factors of Post-0perative Extracorporeal Membrane Oxygenation Support after Lung Transplantation: A Retrospective Analysis
}

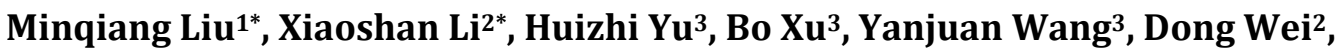 \\ Zhengfeng $\mathrm{Gu}^{3}$, Chunxiao $\mathrm{Hu}^{3 \#}$, Jingyu Chen ${ }^{2}$, Qiang $\mathrm{Wu}^{1 \#}$ \\ ${ }^{1}$ Department of Anesthesiology, The Third People's Hospital of Shenzhen, Shenzhen, China \\ ${ }^{2}$ Department of Lung Transplantation Center, The Affiliated Wuxi People's Hospital of Nanjing Medical University, Wuxi, China \\ ${ }^{3}$ Department of Anesthesiology, The Affiliated Wuxi People's Hospital of Nanjing Medical University, Wuxi, China \\ Email:\#hcx@wuxiph.com,\#45367039@qq.com
}

How to cite this paper: Liu, M.Q., Li, X.S., Yu, H.Z., Xu, B., Wang, Y.J., Wei, D., Gu, Z.F., Hu, C.X., Chen, J.Y. and Wu, Q. (2020) Risk Factors of Post-Operative Extracorporeal Membrane Oxygenation Support after Lung Transplantation: A Retrospective Analysis. Surgical Science, 11, 222-235. https://doi.org/10.4236/ss.2020.118025

Received: July 23, 2020

Accepted: August 25, 2020

Published: August 28, 2020

Copyright (c) 2020 by author(s) and Scientific Research Publishing Inc. This work is licensed under the Creative Commons Attribution-NonCommercial International License (CC BY-NC 4.0). http://creativecommons.org/licenses/by-nc/4.0/ (c) (i) (5) Open Access

\begin{abstract}
Background: Extracorporeal membrane oxygenation (ECMO) is an effective adjuvant therapy for cardiopulmonary support during the period of lung transplantation (LTx). However, factors associated with the application of ECMO after LTx remain controversial. The purpose of this study is to clarify the risk factors of post-operative ECMO support and to evaluate the outcomes. Methods: It was a hospital, single-center, retrospective study. 266 patients underwent LTx supported by ECMO were included. According to whether or not the patients received continourly ECMO support after the surgery, the enrolled patients were further divided into intra-operative ECMO group (group I, 105 cases) and post-operative ECMO group (group $\mathrm{P}, 161$ cases). The peri-operative data of the donors and recipients were collected. The independent risk factors associated with post-operative ECMO support during LTx were identified. The relationship between primary graft dysfunction (PGD)/post-operative survival and duration of ECMO support was also analyzed. Results: Prolonged donor ventilation $\geq 5$ days, pre-operative recipient mechanical ventilation, bilateral lung transplantation (BLT), veno-venous (V-V) ECMO and PGD in recipient were independent risk factors for post-operative ECMO support. The risk of PGD and post-operative death increased along with the increase of ECMO bypass time, and the mortality risk in group P was 2.33 (95\% confidence interval: 1.16 - 4.67) times as that in group I. Conclusions: Mechanical ventilation for donor $\geq 5$ days, pre-operative mechanical ventilation, BLT, V-V-ECMO and PGD in recipient were independent risk factors for post-operative ECMO support after LTx, and post-operative ECMO could not reduce recipients' hospital mortality.
\end{abstract}


Keywords

Risk Factor, Extracorporeal Membrane Oxygenation, Lung Transplantation

\section{Introduction}

Extracorporeal membrane oxygenation (ECMO) has been used for cardiopulmonary support during lung transplantation (LTx) for decades [1]. It is reported that the application of ECMO was conducive to improve oxygenation, stabilize hemodynamics, even serve as a bridge for patients waiting for transplantation [2]. However, due to its own technical characteristics, there are some adverse reactions such as infection, bleeding, renal failure, and nervous system accidents associated with the use of ECMO [3]. As the effect of post-operative ECMO support on the graft function and patients' survival remains controversial [4] [5] [6], ECMO is usually attempted to be removed immediately at the end of LTx in our center. But in some patients with severe respiratory or circulatory insufficiency, it was unsuitable to remove ECMO untimely [7] [8]. In this study, we aim to identify the risk factors for continuous ECMO support after LTx on the basis of peri-operative characteristics and medical data of the donors and the recipients, assessing the outcomes of post-operative ECMO support after LTx, thus to provide references for the clinical practice.

\subsection{Materials and Methods}

It was a hospital, single-center, retrospective study, and was approved by the Medical Ethics Committee of Wuxi People's Hospital, Nanjing Medical University, Wuxi, Jiangsu, China (approval number: RYSX0022). Written informed consent was waived because of the retrospective nature of the research and the anonymity of patients.

\subsection{Graft and Recipient Selection}

All grafts came from volunteer donation after citizen's death in intensive care unit (ICU) after the institutional organ procurement organization approval. No lungs were from executed prisoners. Based on whether or not ECMO was completely stopped in the operating room, recipients were divided into intra-operative ECMO group (group I) and post-operative ECMO group (Group P).

Patients with American Society of Anesthesiologists physical status of Grade IV and scheduled for LTx under planned peripheral ECMO support were reviewed. The exclusion criteria included that, those patients with a history of organ transplantation or combined multiple organ transplantation; patients on central ECMO support; patients had ECMO bypass mode change or received emergency ECMO during the operation; patients experienced traditional cardiopulmonary bypass; patients died during the surgery; patients received ECMO treatment again after removal or accepted ECMO as a bridge to LTx before the 
surgery.

From February 2015 to December 2018, a total of 297 patients were initially assessed for eligibility in this study. Among them, 31 (10.5\%) cases were excluded: including 27 patients on ECMO before anesthesia in ICU, 2 experienced second organ transplantation, and 2 had ECMO bypass mode change during the surgery [ 1 change from veno-arterial ( $\mathrm{V}-\mathrm{A})$ to veno-arterial-venous ( $\mathrm{V}-\mathrm{A}-\mathrm{V}), 1$ from veno-venous (V-V) to V-A-V]. Therefore, a total of 266 (89.5\%) patients were analyzed, including 105 cases in group I and 161 patients in group P.

\subsection{ECMO Support}

All recipients accepted ECMO support after general anesthesia with standard procedure. Firstly, the decision to treat a patient with ECMO or not was assessed by a multidisciplinary team consisting of the LTx surgeons, ECMO intensivisst, and anesthesiologists on the basis of the clinical features including pulse oxygen saturation $\left(\mathrm{SPO}_{2}\right)$, respiratory parameters such as end tidal carbon dioxide partial pressure, tidal volume, and airway pressure under volume controlled ventilation mode via unilateral-lung ventilation, circulatory parameters such as central venous pressure, pulmonary artery pressure (PAP), cardiac index, systemic vascular resistance and pulmonary vascular resistance, and to fully assess the physiological and psychological risks. Secondly, the indications for ECMO included: 1) During one-lung ventilation, the oxygenation could not fully satisfy the physiological needs; 2) The pre-operative systolic PAP exceed $50 \mathrm{mmHg}$ or the mean PAP > $25 \mathrm{mmHg}$; 3) The New York Heart Association cardiac function was grade III to IV; 4) Although the pre-operative cardiopulmonary parameters reached the minimum standard, patients were expected to undergo hemodynamic instability, or hypoxemia during LTx without ECMO support. Thirdly, types of ECMO, including V-V and V-A, either was determined based on patient's clinical features. Normally, in the case of pure oxygen ventilation, if the oxygenation index maintained below $300, \mathrm{~V}-\mathrm{V}$ was selected; if patients were respiratory and hemodynamic instable, V-A was chosen. V-V-ECMO was catheterized from the internal jugular vein for perfusion and the right femoral vein for drainage, while VA-ECMO was established from the right femoral artery as input and the right femoral vein for drainage. In this research, all the selection and application of ECMO were completed before the surgeries. During the period of ECMO bypass, the flow rate was adjusted within $1.5-3.0 \mathrm{~L} / \mathrm{min}$ based on the patient's hemodynamic and oxygenation status. The activated clotting time was monitored every $2 \mathrm{~h}$, and maintained for $160-200 \mathrm{~s}$ by the administration of heparin $10-20 \mathrm{U} / \mathrm{kg}$ when necessary.

\subsection{ECMO Removal}

At the end of LTx, whether ECMO support should be continued was determined based on the recipient's status assessed by the surgeon and anesthesiologist. The ECMO flow was gradually decreased to $0.5 \mathrm{~L} / \mathrm{min}$, if patients were cardiopul- 
monary stable, ECMO was weaned. If the hemodynamics is not stable or the oxygenation index is less than 300, ECMO was maintained and brought into intensive care unit (ICU). In V-V mode, if the oxygenation index was less than 300 , or an acute primary graft dysfunction (PGD) was diagnosed [9], ECMO would be continued. In V-A mode, in addition to the satisfactory of pulmonary function recovery and oxygenation maintenance, if the hemodynamics were not stable, ECMO was maintained.

\subsection{Data Collection}

Risk factors for post-operative ECMO support after LTx were retrospectively collected, including characteristics of the donors and the recipients. Donor variables included gender, age, oxygenation index (partial pressure of oxygen/ fraction of inspired oxygen), mechanical ventilation time, and graft cold ischemia time. Recipient characteristics were analyzed: 1) pre-operative parameters such as gender, age, primary disease, lung allocation score (LAS), partial pressure of oxygen $\left(\mathrm{PO}_{2}\right)$, partial pressure of carbon dioxide $\left(\mathrm{PCO}_{2}\right)$, mean PAP, cardiac functional status, and mechanical ventilation status; 2) surgery-related variables, including procedure type, surgery time, ECMO type, blood loss and transfusion, liquid infusion, and urine production (UPD); 3) post-operative data, including PGD and post-operative hospital survival.

\subsection{Statistical Analyses}

Statistical analyses were performed using the SPSS 22.0 statistical package (SPSS Inc. Chicago, IL, USA, 2013). Data were presented as number and percentage. Univariate analysis including Independent-samples t-test, Mann-Whitney $U$ test, Kruskal-Wallis $H$ test, Chi-square test, and Fisher's exact test was used to compare the difference between group I and group P. Multivariate logistic regression analysis was conducted with a $P<0.1$ in univariate analysis to assess the independent association between the postoperative complications and patients' clinical variables. The odds ratio $(O R)$ and $95 \%$ confidence interval $(C I)$ were reported. Survival data were estimated by Kaplan-Meier curves and compared using Log-rank test. Multivariate cox proportional hazards regression analysis was performed to assess the relationship between PGD/post-operative survival and time of ECMO, the hazard ratio $(H R)$ along with $95 \% C I$ were presented. A value of $P<0.05$ was considered statistically significant.

\section{Results}

\subsection{Basic Clinical Data between Two Groups}

\subsubsection{Donor Characteristics}

As listed in Table 1, compared with group I, more patients in group P had a donor mechanical ventilation time $\geq 5$ days $(48.4 \%$ vs. $24.8 \%, P<0.001)$ and donor graft cold ischemic time $\geq 360$ minutes $(85.7 \%$ vs. $75.2 \%, P=0.031$ ). 
Table 1. Comparison of clinical data between two groups.

\begin{tabular}{|c|c|c|c|c|}
\hline Variables & $\begin{array}{c}\text { Group I } \\
\text { n (\%) }\end{array}$ & $\begin{array}{c}\text { Group P } \\
\text { n (\%) }\end{array}$ & $x^{2}$ & $P$ value \\
\hline \multicolumn{5}{|l|}{ Donor characteristics } \\
\hline Gender & & & 1.224 & 0.269 \\
\hline Male & $92(87.6)$ & $133(82.6)$ & & \\
\hline Female & $13(12.4)$ & $28(17.4)$ & & \\
\hline Age (year) & & & 0.001 & 0.973 \\
\hline$<35$ & $56(53.3)$ & $85(53.1)$ & & \\
\hline$\geq 35$ & $49(46.7)$ & $75(46.9)$ & & \\
\hline Oxygenation index & & & 1.026 & 0.311 \\
\hline$<400$ & $33(31.4)$ & $60(37.3)$ & & \\
\hline$\geq 400$ & $72(68.6)$ & $101(62.7)$ & & \\
\hline Mechanical ventilation time (day) & & & 14.973 & $<0.001$ \\
\hline$<5$ & $79(75.2)$ & $83(51.6)$ & & \\
\hline$\geq 5$ & $26(24.8)$ & $78(48.4)$ & & \\
\hline Graft cold ischemic time (min) & & & 4.641 & 0.031 \\
\hline$<360$ & $26(24.8)$ & $23(14.3)$ & & \\
\hline$\geq 360$ & $79(75.2)$ & $138(85.7)$ & & \\
\hline \multicolumn{5}{|l|}{ Recipient characteristics } \\
\hline Gender & & & 1.365 & 0.243 \\
\hline Male & $90(85.7)$ & $129(80.1)$ & & \\
\hline Female & $15(14.3)$ & $32(19.9)$ & & \\
\hline Age (year) & & & 0.064 & 0.800 \\
\hline$<60$ & $59(56.2)$ & $93(57.8)$ & & \\
\hline$\geq 60$ & $46(43.8)$ & $68(42.2)$ & & \\
\hline Primary disease & & & 11.604 & 0.035 \\
\hline IPF & $75(71.4)$ & $115(71.4)$ & & \\
\hline COPD & $5(4.8)$ & $6(3.7)$ & & \\
\hline Bronchiectasis & $8(7.6)$ & $8(5.0)$ & & \\
\hline Pneumoconiosis & $15(14.3)$ & $13(8.1)$ & & \\
\hline IPH & $1(1.0)$ & $13(8.1)$ & & \\
\hline Others & $1(1.0)$ & $6(3.7)$ & & \\
\hline LAS & & & 2.045 & 0.080 \\
\hline$<50$ & $77(73.3)$ & $119(73.9)$ & & \\
\hline $50-60$ & $15(14.3)$ & $22(13.7)$ & & \\
\hline$\geq 60$ & $13(12.4)$ & $20(12.4)$ & & \\
\hline $\mathrm{PO}_{2}(\mathrm{mmHg})$ & & & 7.869 & 0.020 \\
\hline$<60$ & $38(36.2)$ & $81(50.3)$ & & \\
\hline $60-79$ & $41(39.0)$ & $59(36.6)$ & & \\
\hline$\geq 80$ & $26(24.8)$ & $21(13.0)$ & & \\
\hline $\mathrm{PCO}_{2}(\mathrm{mmHg})$ & & & 2.278 & 0.320 \\
\hline$<35$ & $15(14.3)$ & $23(14.3)$ & & \\
\hline $35-44$ & $43(41.0)$ & $80(49.7)$ & & \\
\hline$\geq 45$ & 47 (44.8) & $58(36.0)$ & & \\
\hline
\end{tabular}




\section{Continued}

Mean PAP (mmHg)
$<25$
$25-35$
$\geq 35$
Cardiac functional status
NYHA I/II
NYHA III/IV

Right ventricular function

$$
\begin{aligned}
& \text { Normal } \\
& \text { Dysfunction }
\end{aligned}
$$

Left ventricular function

$$
\begin{aligned}
& \text { Normal } \\
& \text { Dysfunction }
\end{aligned}
$$

LVEF (\%)

$<60$

$\geq 60$

Mechanical ventilation

$$
\text { Yes }
$$$$
\text { No }
$$

Surgical procedure

$$
\text { SLT }
$$

BLT

Surgery time (min)

$$
<360
$$$$
\geq 360
$$

Type of ECMO

$$
\begin{aligned}
& \text { V-A } \\
& \text { V-V }
\end{aligned}
$$

Blood loss (ml)

$$
\begin{aligned}
& <1000 \\
& \geq 1000
\end{aligned}
$$

Blood transfusion volume (ml)

$$
\begin{aligned}
& <1000 \\
& \geq 1000
\end{aligned}
$$

UPD (ml)

$$
\begin{aligned}
& <1000 \\
& \geq 1000
\end{aligned}
$$

PGD

$$
\text { Yes }
$$

No
2.899 0.419

$20(19.4) \quad 27(16.7)$

$20(19.4) \quad 45(28.0)$

$63(61.2) \quad 89(55.3)$

$87(82.9) \quad 123(76.4)$

$18(17.1) \quad 38(23.6)$

3.946

0.266

$83(79.0) \quad 111(68.9)$

$22(21) \quad .50(31.1)$

$\begin{array}{ll}0.544 & 0.461\end{array}$

$76(72.4) \quad 123(76.4)$

29 (27.6) $\quad 38$ (23.6)

$\begin{array}{ll}2.581 & 0.108\end{array}$

$17(16.5) \quad 40(24.8)$

$86(83.5) \quad 121(75.2)$

3.982

0.046

$4(3.8) \quad 17(10.6)$

$101(96.2) \quad 144(89.4)$

3.722

0.054

$76(72.4) \quad 98(60.9)$

$29(27.6) \quad 63(39.1)$

0.575

0.448

$59(56.2) \quad 98(60.9)$

$46(43.8) \quad 63(39.1)$

13.637

$<0.001$

$91(86.7) \quad 107(66.5)$

$14(13.3) \quad 54(33.5)$

1.873

$53(50.5) \quad 95(59.0)$

$52(49.5) \quad 66(41.0)$

3.287

0.070

$34(32.4) \quad 70(43.5)$

$71(67.6) \quad 91(56.5)$

4.418

0.036

$25(23.8) \quad 58(36.0)$

$80(76.2) \quad 103(64.0)$

14.204

$<0.001$

29 (27.6) $\quad 82(50.9)$

$76(72.4) \quad 79(49.1)$

Data are presented as number (percentage); BLT: bilateral lung transplantation; COPD: chronic obstructive pulmonary disease; ECMO: extracorporeal membrane oxygenation; IPF: idiopathic pulmonary fibrosis; IPH: idiopathic pulmonary hypertension; LAS: lung allocation score; LVEF: left ventricular ejection fraction; NYHA: New York heart association; PAP: Pulmonary arterial pressure; $\mathrm{PaO}_{2}$ : partial pressure of oxygen; $\mathrm{PCO}_{2}$ : partial pressure of carbon dioxide; PGD: primary graft dysfunction; SLT: single lung transplantation; UPD: urine production; $\mathrm{V}$-A: veno-arterial; V-V: veno-venous. 
Donor sex, age, and oxygenation index were not statistically different two groups $(P>0.05)$.

\subsubsection{Recipient Characteristics}

Patients in the I group were more likely to have a primary disease $(P=0.035)$ (Table 1). More patients in Group I had pneumoconiosis ( $8.1 \%$ vs. $14.3 \%)$, but there was a higher proportion of patients primarily diagnosed with idiopathic pulmonary hypertension (IPH) in group P (8.1\% vs. $1.0 \%)$. Moreover, patients in group $\mathrm{P}$ presented with a higher proportion of pre-operative $\mathrm{PO}_{2}<60 \mathrm{mmHg}$ (50.3\% vs. $36.2 \%, P=0.024)$, mechanical ventilation administration $(10.6 \%$ vs. $3.8 \%, P=0.046$ ), V-V-ECMO support (33.5\% vs. $13.3 \%, P<0.001$ ), UPD $<1000$ $\mathrm{ml}(36.0 \%$ vs. $23.8 \%, P=0.036)$, and PGD (50.9\% vs. $27.6 \%, P<0.001)$ compared to group I (Table 1). The recipient gender, age, LAS, pre-operative $\mathrm{PCO}_{2}$, mean PAP, cardiac functional status, right/left ventricular function, LVEF, surgical procedure, surgery time, blood loss and blood transfusion volume, did not show any statistical difference $(P>0.05)$ (Table 1$)$.

\subsection{Risk Factors for Post-Operative ECMO}

The multiple logistic regression analysis showed that mechanical ventilation for donor $\geq 5$ days, pre-operative mechanical ventilation, BLT, V-V-ECMO and PGD in recipient were the independent risk factors for post-operative ECMO after LTx. The OR (95\% CI) of post-operative ECMO support was 4.72 (2.39 9.33), 6.20 (1.23 - 31.21), 2.38 (1.15 - 4.93), 5.48 (2.46 - 12.20), and 2.20 (1.26 3.86) times higher in donor with mechanical ventilation $\geq 5$ days, pre-operative mechanical ventilation, BLT, V-V-ECMO, and PGD for recipient than that in donor mechanical ventilation $<5$ days, none pre-operative mechanical ventilation, SLT, V-A-ECMO, and none PGD for recipient, respectively (Table 2).

After further analysis by multiple cox regression, the risk of PGD was 1.69 (0.91 - 3.14) and $6.99(3.23$ - 15.10) times of ECMO bypass time $24 \mathrm{~h}-48 \mathrm{~h}, \geq 48$ $\mathrm{h}$ as that of ECMO $<24 \mathrm{~h}$, respectively (Table 3 ). The risk of post-operative death was $0.40(0.22-0.72)$ and $0.41(0.24-0.71)$ times of ECMO bypass time < $24 \mathrm{~h}, 24 \mathrm{~h}-48 \mathrm{~h}$ as that of ECMO $\geq 48 \mathrm{~h}$, respectively (Table 4, Figure 1). In addition, the post-operative hospital mortality in group P was 2.33 (95\% CI: 1.16 - 4.67) times as that in group I (Table 4, Figure 2).

\section{Discussion}

Previous studies have reported the efficacy of maintaining ECMO for a period of time after LTx to stable cardiopulmonary function [10]. However, the outcomes for recipients with post-operative ECMO support and factors associated with this procedure remained unclear. The aim of this study is to identify peri-operative crucial risk factors of post-operative ECMO support after LTx, and thus to help make prediction and appropriate interventions in advance. 
Table 2. Multivariate logistic regression analysis of determinants for post-operative ECMO.

\begin{tabular}{|c|c|c|c|c|c|}
\hline Variables & $\beta$ & $S_{\bar{x}}$ & Wald $\chi^{2}$ & $P$ value & OR $(95 \% C D)$ \\
\hline \multicolumn{6}{|c|}{$\begin{array}{l}\text { Mechanical ventilation time } \\
\text { for donor (day) }\end{array}$} \\
\hline$<5$ & & & & & 1.00 \\
\hline$\geq 5$ & 1.55 & 0.35 & 19.93 & $<0.001$ & $4.72(2.39-9.33)$ \\
\hline \multicolumn{6}{|c|}{$\begin{array}{l}\text { Pre-operative mechanical } \\
\text { ventilation for recipient }\end{array}$} \\
\hline Yes & 1.82 & 0.83 & 4.89 & 0.027 & $6.20(1.23-31.21)$ \\
\hline No & & & & & 1.00 \\
\hline \multicolumn{6}{|l|}{ Procedure type } \\
\hline SLT & & & & & 1.00 \\
\hline BLT & 0.87 & 0.37 & 5.42 & 0.020 & $2.38(1.15-4.93)$ \\
\hline \multicolumn{6}{|l|}{ Type of ECMO } \\
\hline V-A & & & & & 1.00 \\
\hline $\mathrm{V}-\mathrm{V}$ & 1.70 & 0.41 & 17.39 & $<0.001$ & $5.48(2.46-12.20)$ \\
\hline \multicolumn{6}{|l|}{ PGD } \\
\hline Yes & 0.790 & 0.287 & 7.589 & 0.006 & $2.20(1.26-3.86)$ \\
\hline No & & & & & 1.00 \\
\hline
\end{tabular}

BLT: bilateral lung transplantation; CI: confidence interval; ECMO: extracorporeal membrane oxygenation; OR: odds ratio; PGD: primary graft dysfunction; SLT: single lung transplantation; V-A: veno-arterial; V-V: veno-venous.

Table 3. Multiple cox regression analysis of determinants of post-operative PGD.

\begin{tabular}{lccccc}
\hline \multicolumn{1}{r}{ Variables } & $\beta$ & $S_{\bar{x}}$ & Wald $\chi^{2}$ & $P_{\text {value }}$ & $H R(95 \% C I)$ \\
\hline Time of ECMO (h) & & & & & \\
$\quad<24$ & & & & & 1.00 \\
$24-48$ & 0.52 & 0.32 & 2.73 & 0.099 & $1.69(0.91-3.14)$ \\
$\geq 48$ & 1.94 & 0.39 & 24.47 & $<0.001$ & $6.99(3.23-15.10)$ \\
\hline
\end{tabular}

CI: confidence interva; ECMO: extracorporeal membrane oxygenation; HR: hazard ratio.

Table 4. Multiple cox regression analysis of determinants of post-operative death.

\begin{tabular}{lccccc}
\hline \multicolumn{1}{c}{ Variables } & $\beta$ & $S_{\bar{x}}$ & Wald $\chi^{2}$ & $P$ value & HR $(95 \% C D)$ \\
\hline Time of ECMO (h) & & & & & \\
$\quad<24$ & -0.92 & 0.30 & 9.28 & $\mathbf{0 . 0 0 2}$ & $0.40(0.22-0.72)$ \\
$\quad 24-48$ & -0.89 & 0.28 & 10.26 & $\mathbf{0 . 0 0 1}$ & $0.41(0.24-0.71)$ \\
$\quad \geq 48$ & & & & & 1.00 \\
Group & & & & & 1.00 \\
$\quad \begin{array}{l}\text { Intra-operative ECMO } \\
\quad \text { Post-operative ECMO }\end{array}$ & 0.84 & 0.36 & 5.62 & $\mathbf{0 . 0 1 8}$ & $2.33(1.16-4.67)$ \\
\hline
\end{tabular}

CI: confidence interva; ECMO: extracorporeal membrane oxygenation; HR: hazard ratio. 


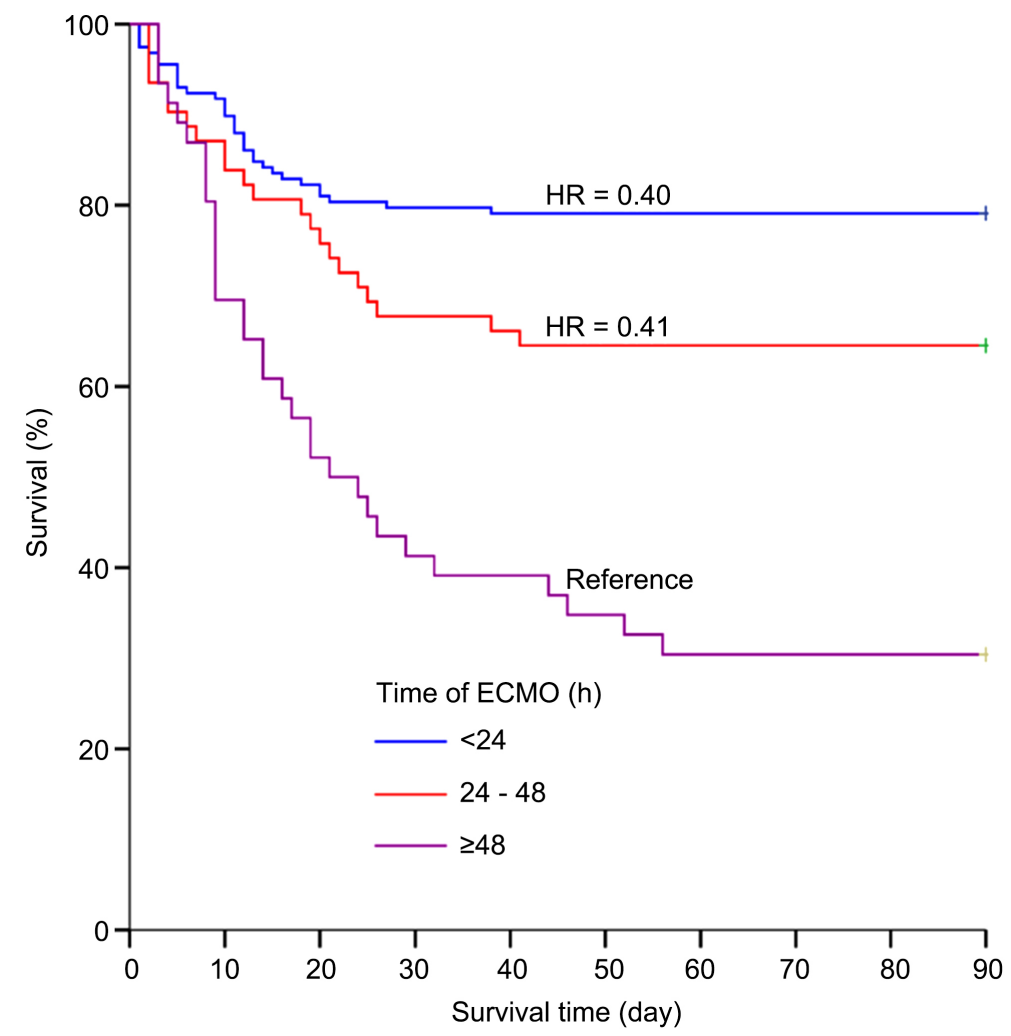

Figure 1. Post-operative death among the various bypass time of ECMO.

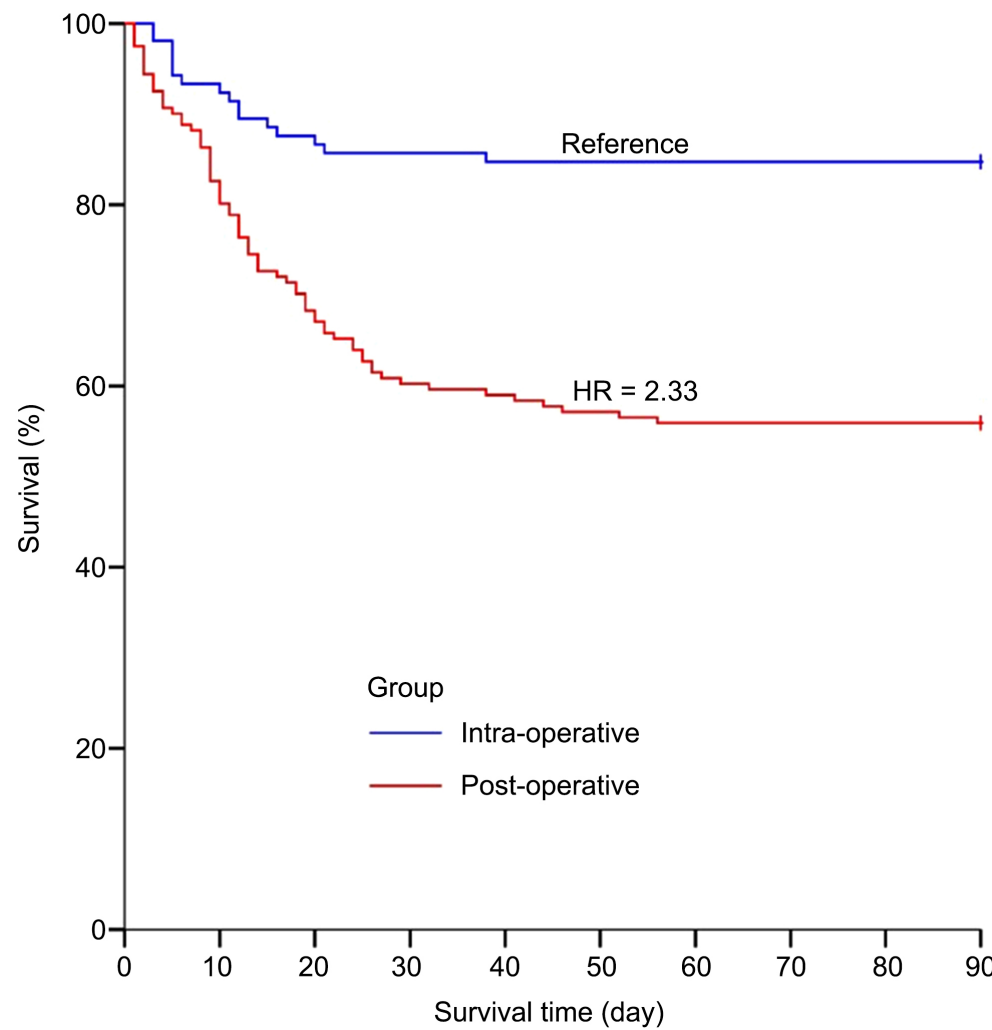

Figure 2. Comparison of post-operative death between intra-operative and post-operative group. 
Herein we found that, when donors were intubated over 5 days, this was an independent risk factor for continuous post-operative ECMO treatment. This might be related to all grafts came from brain-dead donors in ICU, who usually received mechanical ventilation for a period of time until surgery. A long term mechanical ventilation might have adverse effects on the donor lung, and the incidence of potential ventilator-associated lung injury and infection increased over time [11] [12]. Thus, a long duration of intubation in donors was recognized to play an important role for prolonged ECMO support after LTx.

It was previously reported that the cold ischemic time of the donor lung should be limited to less than 6 hours [13] [14]. As time went by, hypoxia and edema of the donor lung gradually worsen, and effective pulmonary function cannot be restored in time after the opening of the transplanted blood vessel, resulting in hypoxemia and graft dysfunction [15] [16]. The first analysis in this research indicated that patients who continued to use ECMO after surgery, who were usually transplanted with grafts on long duration of cold ischemia $(\geq 360$ minutes). Usually, this may be due to patient received BLT. During BLT, the second lung always experiences a longer ischemic period, and that may lead to a worse ischemia-reperfusion injury after the opening of the transplanted vessels [17] [18] [19]. Consequently, the incidence of graft dysfunction increased, and ECMO was often needed after this procedure. Herein the following analysis identified BLT as a crucial factor for post-operative ECMO support. This suggested that patients receiving BLT usually needed longer ECMO support for graft recovery.

With regard to recipients' primary diseases, this research showed that patients with pneumoconiosis were more likely to have early removal of ECMO support after surgery, but patients with idiopathic pulmonary hypertension (IPH) often needed prolonged ECMO. The possible reason for this was that pneumoconiosis patients had less cardiac insufficiency [20], but patients with IPH were more complicated, often with severe right ventricular dysfunction that may lead to the requirement for ECMO, even before anesthesia [21] [22]. However, this single-center retrospective study was done in a cohort, the primary disease of recipients was mainly diagnosed as idiopathic pulmonary fibrosis $(>70 \%)$, and the total proportion of IPH was extremely low $(<5 \%)$, the follow-up analysis did not show any statistically significant differences related to primary disease. In the future, larger-scale studies that include multiple diseases are needed on these subjects.

Clinically, a $\mathrm{PaO}_{2}$ below $60 \mathrm{mmHg}$ is diagnosed as respiratory failure [23]. In this study, all patients suffered from severe respiratory insufficiency; however, although the pre-operative $\mathrm{PaO}_{2}$ was statistically different in the two groups in the initial analysis, the follow-up analysis did not demonstrate $\mathrm{PaO}_{2}$ as a key factor affecting the removal of ECMO. The possible explanation for this was that all patients received either nasal catheter aspiration or ventilator therapy before anesthesia, these treatments improve patients' oxygenation, but their actual $\mathrm{PaO}_{2}$ 
levels may have a further distinction without oxygen therapy. On the other hand, during the peri-operative period, patients received ventilator care before anesthesia often implies severe illness and poor prognosis [24]. Our results suggested that pre-operative mechanical ventilation of the recipient was also a decisive factor for ECMO support after surgery, the main consideration was that the lung and general condition of these recipients were extremely poor, and even if LTx was performed, the effective oxygenation of the grafts cannot be restored in time, and prolonging ECMO after LTx tend to be a good choice.

$\mathrm{V}-\mathrm{V}$ and $\mathrm{V}-\mathrm{A}$ are the most widely used types of ECMO. The results of this study showed that the V-V mode was $5.48(2.46-12.20)$ times more difficult to remove after LTx than V-A, this may be due to the fact that the incidence of PGD was significantly higher in group P. As the current mainstream views stated that ECMO treatment during LTx was in favor of the graft function (expecially in a V-V mode), [5] [10] ECMO support would be continued when PGD immediately occurred at the end of the surgery in patients admitted in our center. Moreover, researches had reported that patients treated with V-V-ECMO usually suffer from worse pulmonary function, but the adverse event caused by $\mathrm{V}-\mathrm{V}$ was relatively less than V-A mode [25] [26], thus, when a decision needed to be made regarding whether or not to continue ECMO support at the end of surgery, it is easier for the clinicians to maintain V-V-ECMO.

The results also showed that both the risk of PGD and post-operative death increased with the rise of ECMO bypass time, especially when the bypass time was over $48 \mathrm{~h}$, indicating that although post-operative ECMO support might improve the cardiopulmonary function to some extent, it could not reduce recipients' hospital mortality. This was consistent with the current reports that a long duration of ECMO support after LTx could not improve the early prognosis [27] [28]. When the bypass time was over 2 days, it usually meant that the whole condition of the recipients was extremely poor or the donor lung function was incomplete. Hence, clinicians should pay attention to ECMO bypass time, even try to give up this procedure when the duration of ECMO was more $48 \mathrm{~h}$ if necessary for the high hospital mortality.

There were some limitations in this research. Firstly, 27 cases (9\%) received ECMO before anesthesia was excluded in this research because ECMO was routinely maintained for a few days after LTx for cardiopulmonary support in these patients in our center, regardless of their immediate state at the end of the surgery. To ensure that patients included in this research accepted the same criterion of ECMO removal, we excluded these cases, but this may lead to a potential bias of the statistical results. Secondly, we did not classify the flow rate of pre-operative oxygen inhalation by nasal catheter, and the scale of recipients receiving pre-operative mechanical ventilation was also very low $(<10 \%)$, we did not go further analysis on these subjects, that may limit the generalizability of the findings. Therefore, a multi-center, and larger sample analysis should be conducted in future to minimize deviation. 


\section{Conclusion}

In conclusion, mechanical ventilation for donor $\geq 5$ days, pre-operative mechanical ventilation, BLT, V-V-ECMO and PGD in recipient were independent risk factors for post-operative ECMO support after LTx, and post-operative ECMO could not reduce recipients' hospital mortality.

\section{Acknowledgements}

Thanks to editage by cactus (https://support.online.editage.com/) for the English edit in this study.

\section{Data availability Statement}

The data used to support the findings of this study are available from the corresponding author upon request.

\section{Funding}

Funding by Chen Jingyu Team of Sanming Project of Medicine in Shenzhen (No. SZSM201812058).

\section{Conflicts of Interest}

The authors declare no conflicts of interest regarding the publication of this paper.

\section{References}

[1] Lepper, P.M., Barrett, N.A., Swol, J., et al. (2020) Perception of Prolonged Extracorporeal Membrane Oxygenation in Europe: An EuroELSO Survey. Perfusion, 35 , 81-85. https://doi.org/10.1177/0267659120909740

[2] López Sánchez, M. and Rubio López, M.I. (2018) Extracorporeal Membrane Oxygenation as a Bridge to Lung Transplantation. Archivos de Bronconeumología, 54, 599-600. https://doi.org/10.1016/j.arbres.2018.04.011

[3] Zangrillo, A., Landoni, G., Biondi-Zoccai, G., et al. (2013) A Meta-Analysis of Complications and Mortality of Extracorporeal Membrane Oxygenation. Critical Care \& Resuscitation, 15, 172-178.

[4] Na, S.J., Jung, J.S., Hong, S.B., et al. (2019) Clinical Outcomes of Patients Receiving Prolonged Extracorporeal Membrane Oxygenation for Respiratory Support. Therapeutic Advances in Respiratory Disease, 13, 1753466619848941. https://doi.org/10.1177/1753466619848941

[5] Moser, B., Jaksch, P., Taghavi, S., et al. (2018) Lung Transplantation for Idiopathic Pulmonary Arterial Hypertension on Intraoperative and Postoperatively Prolonged Extracorporeal Membrane Oxygenation Provides Optimally Controlled Reperfusion and Excellent Outcome. European Journal of Cardio-Thoracic Surgery, 53, 178-185. https://doi.org/10.1093/ejcts/ezx212

[6] García-Gigorro, R., Renes-Carreño, E., Pérez-Vela, J.L., et al. (2017) Mechanical Support with Venoarterial Extracorporeal Membrane Oxygenation (ECMO-VA): Short-Term and Long-Term Prognosis after a Successful Weaning. Medicina Intensiva, 41, 513-522. https://doi.org/10.1016/j.medin.2016.12.013 
[7] Song, J.H., Park, J.E., Lee, J.G., et al. (2017) Outcomes of Perioperative Extracorporeal Membrane Oxygenation Use in Patients Undergoing Lung Transplantation. Journal of Thoracic Disease, 9, 5075-5084. https://doi.org/10.21037/jtd.2017.10.142

[8] Zwischenberger, J.B. and Pitcher, H.T. (2017) Extracorporeal Membrane Oxygenation Management: Techniques to Liberate from Extracorporeal Membrane Oxygenation and Manage Post-Intensive Care Unit Issues. Critical Care Clinics, 33, 843-853. https://doi.org/10.1016/j.ccc.2017.06.006

[9] Snell, G.I., Yusen, R.D., Weill, D., et al. (2017) Report of the ISHLT Working Group on Primary Lung Graft Dysfunction, Part I: Definition and Grading-A 2016 Consensus Group Statement of the International Society for Heart and Lung Transplantation. The Journal of Heart and Lung Transplantation, 36, 1097-1103. https://doi.org/10.1016/j.healun.2017.07.021

[10] Hoetzenecker, K., Schwarz, S., Muckenhuber, M., et al. (2018) Intraoperative Extracorporeal Membrane Oxygenation and the Possibility of Postoperative Prolongation Improve Survival in Bilateral Lung Transplantation. Journal of Thoracic and Cardiovascular Surgery, 155, 2193-2206.e3. https://doi.org/10.1016/j.jtcvs.2017.10.144

[11] Tang, C., Li, J., Lei, S., et al. (2017) Lung-Protective Ventilation Strategies for Relief from Ventilator-Associated Lung Injury in Patients Undergoing Craniotomy: A Bicenter Randomized, Parallel, and Controlled Trial. Oxidative Medicine and Cellular Longevity, 2017, Article ID: 6501248. https://doi.org/10.1155/2017/6501248

[12] Kuchnicka, K. and Maciejewski, D. (2013) Ventilator-Associated Lung Injury. Anaesthesiology Intensive Therapy, 45, 164-170. https://doi.org/10.5603/AIT.2013.0034

[13] Thabut, G., Mal, H., Cerrina, J., et al. (2005) Graft Ischemic Time and Outcome of Lung Transplantation: A Multicenter Analysis. American Journal of Respiratory and Critical Care Medicine, 171, 786-791. https://doi.org/10.1164/rccm.200409-1248OC

[14] Hayes, D., Joy, B.F., Reynolds, S.D., et al. (2016) Influence of Graft Ischemic Time and Geographic Distance between Donor and Recipient on Survival in Children after Lung Transplantation. The Journal of Heart and Lung Transplantation, 35, 1220-1226. https://doi.org/10.1016/j.healun.2016.05.018

[15] Fiser, S.M., Kron, I.L., Long, S.M., et al. (2001) Influence of Graft Ischemic Time on Outcomes Following Lung Transplantation. The Journal of Heart and Lung Transplantation, 20, 1291-1296. https://doi.org/10.1016/S1053-2498(01)00355-2

[16] Hayes, D., Tumin, D., Kopp, B.T., et al. (2016) Influence of Graft Ischemic Time on Survival in Children with Cystic Fibrosis after Lung Transplantation. Pediatric Pulmonology, 51, 908-913. https://doi.org/10.1002/ppul.23432

[17] Mishra, A., Reed, R.M. and Eberlein, M. (2016) Severe, Rapidly Reversible Hypoxemia in the Early Period after Bilateral Lung Transplantation. Annals of the American Thoracic Society, 13, 979-985. https://doi.org/10.1513/AnnalsATS.201602-107CC

[18] De Oliveira, N.C., Osaki, S., Maloney, J., et al. (2012) Lung Transplant for Interstitial Lung Disease: Outcomes for Single versus Bilateral Lung Transplantation. Interactive Cardio Vascular and Thoracic Surgery, 14, 263-267. https://doi.org/10.1093/icvts/ivr085

[19] Bittner, H.B., Boyer, J.H., Ledzian, B., et al. (2015) Unusual Indication for Extracorporeal Membrane Oxygenation Immediately after Successful Sequential Bilateral Lung Transplantation: A Case Report. Transplantation Proceedings, 47, 849-851. 
https://doi.org/10.1016/j.transproceed.2014.12.015

[20] Yen, C.M., Lin, C.L., Lin, M.C., et al. (2016) Pneumoconiosis Increases the Risk of Congestive Heart Failure: A Nationwide Population-Based Cohort Study. Medicine (Baltimore), 95, e3972. https://doi.org/10.1097/MD.0000000000003972

[21] Tsai, M.T., Hsu, C.H., Luo, C.Y., et al. (2015) Bridge-to-Recovery Strategy Using Extracorporeal Membrane Oxygenation for Critical Pulmonary Hypertension Complicated with Cardiogenic Shock. Interactive CardioVascular and Thoracic Surgery, 21, 55-61. https://doi.org/10.1093/icvts/ivv070

[22] Brewis, M.J., Church, A.C., Johnson, M.K., et al. (2015) Severe Pulmonary Hypertension in Lung Disease: Phenotypes and Response to Treatment. European Respiratory Journal, 46, 1378-1389. https://doi.org/10.1183/13993003.02307-2014

[23] Cinesi-Gómez, C., García-García, P., López-Pelayo, I., et al. (2017) Correlation between Oxyhaemoglobin Saturation by Pulse Oximetry and Partial Pressure of Oxygen in Patients with Acute Respiratory Failure. Revista Clínica Española, 217, 522-525. https://doi.org/10.1016/j.rce.2017.08.006

[24] Sun, H., Zhou, Y., Xiong, H., et al. (2015) Prognosis of Very Preterm Infants with Severe Respiratory Distress Syndrome Receiving Mechanical Ventilation. Lung, 193, 249-254. https://doi.org/10.1007/s00408-014-9683-5

[25] Puri, N., Baram, M. and Cavarocchi, N.C. (2017) Extracorporeal Membrane Oxygenation. Critical Care Clinics, 33, 11-12. https://doi.org/10.1016/j.ccc.2017.07.002

[26] Lafç, G., Budak, A.B., Yener, A.Ü., et al. (2014) Use of Extracorporeal Membrane Oxygenation in Adults. Heart, Lung and Circulation, 23, 10-23. https://doi.org/10.1016/j.hlc.2013.08.009

[27] Boffini, M., Simonato, E., Ricci, D., et al. (2019) Extracorporeal Membrane Oxygenation after Lung Transplantation: Risk Factors and Outcomes Analysis. Annals of Cardiothoracic Surgery, 8, 54-61. https://doi.org/10.21037/acs.2018.12.10

[28] Bellier, J., Lhommet, P., Bonnette, P., et al. (2019) Extracorporeal Membrane Oxygenation for Grade 3 Primary Graft Dysfunction after Lung Transplantation: Long-Term Outcomes. Clinical Transplantation, 33, e13480.

https://doi.org/10.1111/ctr.13480 